\title{
Rows of Dislocation Loops in Aluminium Irradiated by Aluminium lons
}

\author{
Henriksen, L.; Johansen, A.; Koch, J.; Andersen, H. H.; Cotterill, Rodney M J
}

Published in:

Applied Physics Letters

Link to article, DOI:

$10.1063 / 1.1755066$

Publication date:

1967

Document Version

Publisher's PDF, also known as Version of record

Link back to DTU Orbit

Citation (APA):

Henriksen, L., Johansen, A., Koch, J., Andersen, H. H., \& Cotterill, R. M. J. (1967). Rows of Dislocation Loops in Aluminium Irradiated by Aluminium lons. Applied Physics Letters, 11(4), 136-138.

https://doi.org/10.1063/1.1755066

\section{General rights}

Copyright and moral rights for the publications made accessible in the public portal are retained by the authors and/or other copyright owners and it is a condition of accessing publications that users recognise and abide by the legal requirements associated with these rights.

- Users may download and print one copy of any publication from the public portal for the purpose of private study or research.

- You may not further distribute the material or use it for any profit-making activity or commercial gain

- You may freely distribute the URL identifying the publication in the public portal

If you believe that this document breaches copyright please contact us providing details, and we will remove access to the work immediately and investigate your claim 
tron microscopy of the silicon samples and are indebted to R. R. Papania and H. D. Larson for their able technical assistance.

${ }^{1}$ G. R. Booker and R. Stickler, J. Appl. Phys. 33, 3281 (1962).

${ }^{2}$ G. R. Booker and B. A. Unvala, Phil. Mag. 11, 11 (1965).
${ }^{3}$ S. Mendelson, in Single Crystal Films (M. H. Francombe and H. Sato, Eds.), p. 251 , Pergamon Press, Oxford, 1963.

${ }^{4} \mathrm{H}$. Widmer, Appl. Phys. Letters 5, 108 (1964).

${ }^{5}$ R. N. Thomas and M. H. Francombe, Appl. Phys. Letters 11, 108 (1967).

${ }^{6} \mathrm{~T}$. N. Rhodin, in The Use of Thin Films in Physical Investigations (J. C. Anderson, Ed.), p. 187, Academic Press, London, 1966.

\title{
ROWS OF DISLOCATION LOOPS IN ALUMINIUM IRRADIATED BY ALUMINIUM IONS
}

\author{
L. Henriksen, A. Johansen and J. Koch \\ Physical Laboratory II, H. C. Oersted Institute \\ University of Copenhagen, Denmark
}

\section{H. H. Andersen and R. M. J. Cotterill* \\ The Technical University Lyngby, Denmark} and

Danish Atomic Energy Commission, Research Establishment Ris $\emptyset$ (Received 26 June 1967)

\begin{abstract}
Single-crystal aluminium specimens, irradiated with $50-\mathrm{keV}$ aluminium ions, contain dislocation loops that are
\end{abstract} arranged in regular rows along $(110)$ directions.

The two most common techniques used to produce point defects in metals are quenching and irradiation with energetic particles. The former produces essentially only vacancies while the latter normally gives equal numbers of vacancies and interstitials. If, however, the irradiating particles are ions of the same elements as the target material these atoms will become interstitials if they come to rest in the target. This type of irradiation, therefore, produces more interstitials than vacancies, although the relative difference will in practice be negligible everywhere except in the region where the majority of the ions come to rest. This Letter reports experiments in which dislocation loops were produced in pure aluminium by irradiation with aluminium ions.

Single crystal aluminium specimens, thin enough to be examined by transmission electron microscopy, were irradiated with $50 \mathrm{keV}$ aluminium ions. Crystals of nominal purity $99.9999 \%$, and with surface normals oriented within $2^{\circ}$ of either a $\langle 110\rangle$ or a $\langle 111\rangle$ direction were used. During each irra-

\footnotetext{
* On leave from Argonne National Laboratory, Argonne, Illinois, presently back at Argonne National Laboratory (work supported in part by the U.S. Atomic Energy Commission).
}

diation the ion beam was at right angles to the plane of the specimen to better than $1^{\circ}$. In all cases the specimen was examined in the electron microscope both before and after irradiation. Both types of crystal were irradiated at room temperature with fluxes in the range $1 \times 10^{11}-1 \times 10^{14} \mathrm{~cm}^{-2}$ $\sec ^{-1}$ and doses from $6 \times 10^{12}$ to $6 \times 10^{14} \mathrm{~cm}^{-2}$. For specimens of either orientation the irradiation is found to produce rows of dislocation loops parallel to $\langle 110\rangle$ directions. At low magnification (see Fig. 1) these rows are quite easily distinguished. Higher magnifications (see Fig. 2) allow the individual loops to be resolved. Neither the spacing between the rows nor the regular spacing of individual loops within a row is dependent upon the dose, but the radii of the loops increase with dose. Within about $5000 \AA$ of the edge the loop distribution differed from that observed in the rest of the specimen. The spacing between the rows fell to about half its normal value, and the overall loop density was approximately doubled. For the lowest flux, and with a dose of $6 \times 10^{13} \mathrm{~cm}^{-2}$ the $\langle 111\rangle$ specimens were found to contain isolated loops and no rows. Specimens of the $\langle 111\rangle$ orientation were also irradiated at a nominal temperature of $78^{\circ} \mathrm{K}$ with fluxes in the range $1 \times 10^{12}-1 \times 10^{14}$ 
$\mathrm{cm}^{-2} \mathrm{sec}^{-1}$ at a standard dose of $6 \times 10^{14} \mathrm{~cm}^{-2}$. The highest flux produced the rows of loops. For fluxes in the range $1 \times 10^{12}-1 \times 10^{13} \mathrm{~cm}^{-2}$, however, no rows of loops were observed. This treatment was found to produce the complex tangles of dislocations which have been the characteristic observation of the related type of experiment in which a target of one element was irradiated with ions of a different element. ${ }^{1}$ The actual temperature of the specimen during irradiation was not known. Heating effects would increase with irradidtion flux, and this might explain why the highest flux produced a defect distribution which was more characteristic of the room temperature irradiations. To check that orientation is an important factor, polycrystalline specimens were irradiated under similar conditions. Individual grains, in which low index directions were not close to the direction of the ion beam, were examined and found to contain complex tangles of dislocations ${ }^{1}$ and occasional isolated loops. No rows of loops were observed in these grains.

The appearance of rows of loops under certain

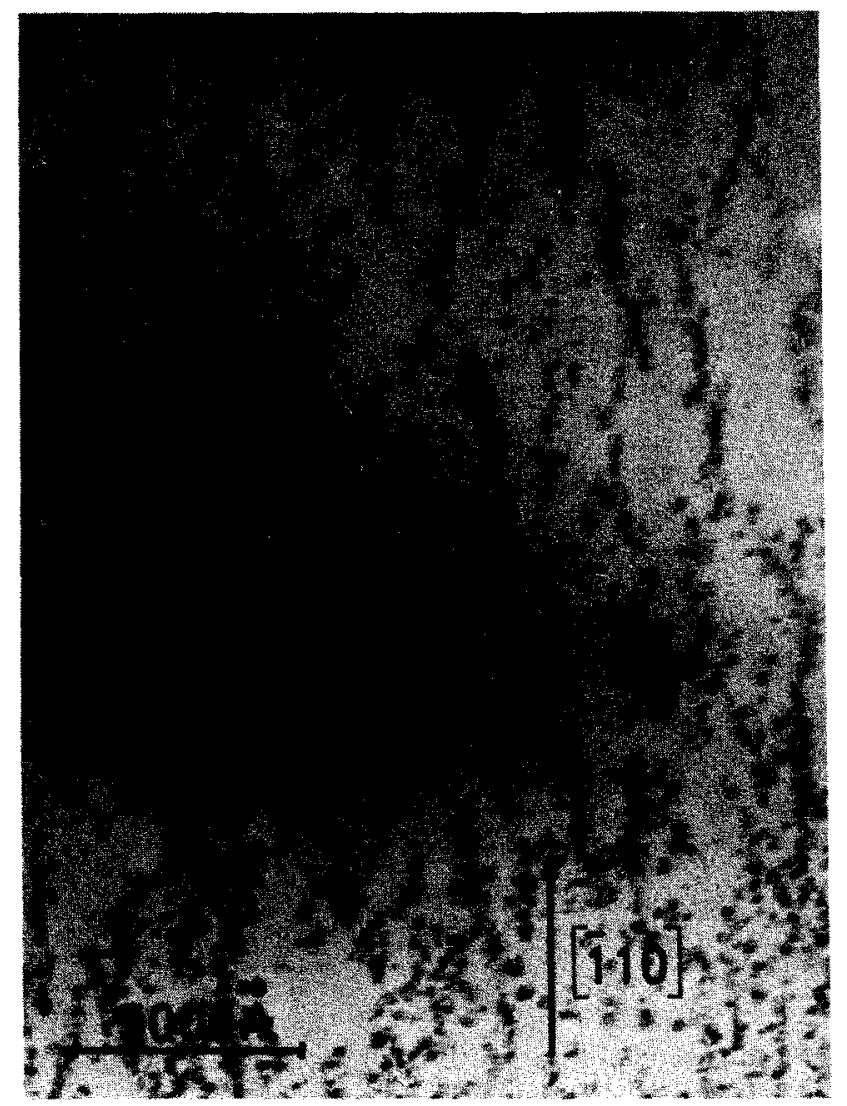

Fig. 1. An area of a (111) specimen irradiated at a flux of $1 \times 10^{12}$ ions $\mathrm{cm}^{-2} \mathrm{sec}^{-1}$ and a dose of $6 \times 10^{14}$ ions $\mathrm{cm}^{-2-2}$. The lower edge of the picture lies close to the edge of the specimen. conditions of ion irradiation has not been reported previously. The experiments described here involved two novel features in that the targets were both single crystals and of the same element as the irradiating ions. The observations indicate that specimen orientation is an important factor. Experiments are now in progress in which the target and the irradiating ions are of different elements to see whether the rows are still produced under such conditions. The fact that the rows of loops always lie along $\langle 110\rangle$ directions is rather suggestive. Both focusing ${ }^{2}$ and channeling ${ }^{3}$ processes are known to be most favorable along these directions. The length of the rows is usually of the order of $5000 \AA$, however, whereas focusing is generally believed to occur over distances an order of magnitude smaller than this. If each row is associated with a single directional event, therefore, focusing can be ruled out. Channeling on the other hand is thought to occur over distances as large as the lengths of the rows of loops. From determinations of the range distributions of $40 \mathrm{keV}$ $\mathrm{Na}^{24}$ ions in aluminium, ${ }^{5}$ one can make the rough

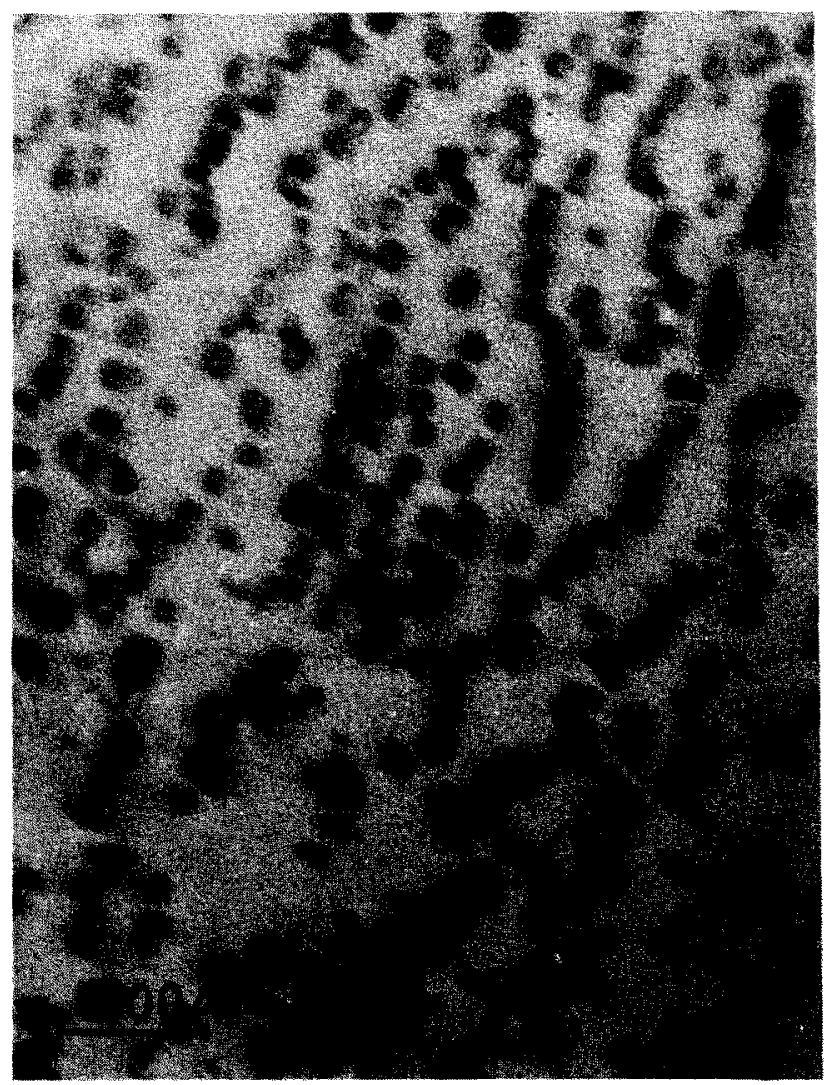

Fig. 2. Another area of the specimen shown in Fig. 1. Individual loops are resolved. This area is close to the edge of the specimen and the rows are more closely spaced. 
estimate that the maximum range of aluminium ions in the $\langle 110\rangle$ direction of an aluminium target is about $11000 \AA$. Approximately $5 \%$ of the ions would have ranges in excess of $5000 \AA$. The constant spacing between the rows, the constant spacing of individual loops within a row, and the constancy of the length of the rows, all for a range of different doses and fluxes, suggests that the rows are nucleated at an early stage during the irradiation. This too indicates a connection with channeling. Channeling of the irradiating ions will be most efficient when the crystal is still rather perfect and relatively free of irradiation damage.

The exact mechanism of the formation of the rows is not yet understood. Experiments aimed at determining whether the loops are of the vacancy or interstitial type are now in progress, and in ad- dition irradiations are being carried out at $4^{\circ} \mathrm{K}$ in an effort to obtain a more clearly defined temperature dependence of the various effects.

We thank T. H. Blewitt, N. Hansen, A. R. Mackintosh and K. Særmark for their interest and encouragement, $K$. Persson for supervising the ion irradiations, and T. Leffers and J. Lindbo for help in specimen preparation.

'P. B. Bowden and D. G. Brandon, Phil. Mag. 8, 935 (1963).

${ }^{2}$ R. H. Silsbee, J. Appl. Phys. 28, 1246 (1957).

${ }^{3}$ Chr. Lehmann and G. Leibfried, J. Appl. Phys. 34, 2821 (1963).

${ }^{4}$ R. S. Nelson and M. W. Thompson, Phil. Mag. 7, 1425 (1962).

${ }^{5}$ G. R. Piercy, M. McCargo, F. Brown and J. A. Davies, Can. J. Phys. 42, 1176 (1964).

\title{
THE DIRECT ABSORPTION EDGE IN COVALENT SOLIDS*
}

\author{
David Redfield $\dagger$ and Martin A. Afromowitz \\ School of Engineering and Applied Science \\ Columbia University \\ New York, N. Y. \\ (Received 10 July 1967)
}

\begin{abstract}
Comparative measurements of the absorption edge of $p$-type GaAs and compensated GaAs over a wide temperature range demonstrate that the shape of the edge in such materials is not dependent on phonon interactions, and is attributable to the state of charge of impurities in the material.
\end{abstract}

It is well known that fundamental optical absorption edges formed by direct band-to-band transitions should be characterized by the form $K(\hbar \omega-$ $\left.E_{G}\right)^{1 / 2}$ at photon energies $\hbar \omega$ close to the energy gap $E_{G_{i}}$. The constant $K$ contains the matrix element, joint densities of states in the valence and conduction bands, etc. In practice, however, this form is almost never observed. Instead, the usual absorption edge does not have an abrupt threshold at $E_{G}$ but a "tail" whose dependence on $\hbar \omega$ is very nearly exponential and which extends to energies below $E_{i}$. There have been numerous attempts to explain this phenomenon, most commonly by invoking phonon interactions. ${ }^{1}$ The present Letter presents experimental evidence of a very direct nature showing that in predominantly covalent materials these exponential absorption edges are not related to phonons but rather to the state of charge of imperfections in the material.

*Supported in part by the U. S. Office of Naval Research. †Present address: RCA Laboratories, Princeton, N. J.
The essential feature of the present experiments is the comparison of the absorption edge of ordinary, impure GaAs with the edge of similar, but compensated $\mathrm{GaAs}$ over a wide temperature range. The experimental considerations of consequence here were the very low stray light in the optical system and the thermal exchange gas surrounding the samples to establish stable and readily measurable sample temperatures.

The principle of these experiments is straightforward. If an ordinary, impure crystal is cooled sufficiently to freeze-out the free carriers, they will be recaptured by the fixed impurity centers from which they came and neutralize these centers. Such neutralization should reduce the absorption edge tails if the electric fields of the charged centers are responsible for the tails as has been proposed for covalent solids. ${ }^{2}$ In Fig. 1 it is seen that this is indeed observed: The slope of the absorption edge increases monotonically as the temperature diminishes. (The shift in position represents the temperature dependence of the energy gap and is 